\title{
DFT Conformational Study of Calix[5] arene and Calix[4]arene: Hydrogen Bond
}

\author{
Kwangho Kim, Seong Jun Park, and Jong-In Choe* \\ Department of Chemistry, Ching-Ang University, Seoul 156-756. Korea. 'E-mail: choejlacaudack' \\ Received hily:8, 2008
}

\begin{abstract}
We have perfomed DFT calculations to investigate the confomational characteristics and hydrogen bonds of the $p$-tert-butylcalix[5] arene (1) and p-tert-butylcalix[4]arene (2). The structures of different conforners of 1 were optimized by using B3LYP/6-31+G(d,p) method. The relative stability of the various conforners of 1 is in the following order: cone (most stable) $>1,2$-altemate $>$ partial-cone $>1,3$-altemate. The relative stability of four conformers of 2 is in the following order: cone (most stable) $>$ partial-cone $>1,2$-alternate $>1,3$-altemate. The primary factor affecting the relative stabilities of the various conformers of the $\mathbf{1}$ and $\mathbf{2}$ are the number and strength of the intramolecular hydrogen bonds. The hydrogen-bond distances are discussed based on different calculation methods.
\end{abstract}

Key Words : DFT, B3LYP/6-31+G, Calix[5]arene, Calix[4]arene, Confomer, Hydrogen bond

\section{Introduction}

The calixarenes are particularly attractive as a basic skeleton for new supramolecular systems due to their welldefined molecular framework. ${ }^{l}$ Among the varying structures of calixarenes, pentameric analogue calix [5]arenes ${ }^{2,3}$ has received relatively less attention due to their difficulties both in the synthesis and in the selective derivatization compared to the other widely employed members of calixarenes having four, six, or eight repeating units. The relative stabilities of the various conformations of calix[4]aryl derivatives are determined by experimental and theoretical methods. ${ }^{4-4}$ Previously, the relative stability of calix systems was reported ${ }^{10}$ For calix[4]quinone (CQ) and calix[4]hydroquinone $(\mathrm{CHQ})$, the order in stability is as follows: $\mathrm{CQ}$ : partial cone $>1.3$ alternative $>$ cone $>1,2$ alternative, $\mathrm{CHQ}$ : cone $>$ partial cone $>1,2$-alternative $>1,3$-alternative

We reported the calculation results for the molecular recognition behaviors of penta-O-alkylated derivative of cone-shaped p-tert-butylcalix[5]arene toward a series of alkyl ammonium guests. ${ }^{11,12}$

The first objective of this research is to determine the relative stability of different conformational isomers for $p$ tert-butylcalix[5]arene ${ }^{2 b}(1)$ and $p$-tert-butylcalix[4] arene ${ }^{t}$ (2) by using DFT calculation. The second objective is to investigate the intramolecular hydrogen bonds by the
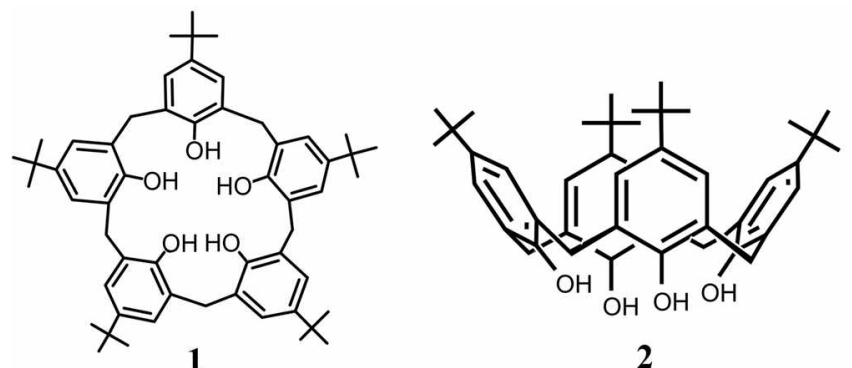

2

Chart 1. ChemDraw Structures of $p$-tert-Butylcalix[5]arene (1) and the cone conformer of $p$-tert-Butylcalix[4]arene (2). hydroxyl groups of the 1 and 2 using different calculation methods

\section{Computational Methods}

The initial structures of p-tert-butylcalixarenes ( 1 and 2 ) were constructed by using HyperChem. ${ }^{13}$ In order to find optimized conformations, we executed a conformational search by using a simulated annealing method, which has been described in a previous publication. ${ }^{1+}$ The conformational isomers of 1 and 2 obtained from MM/MD and AM1 semi-empirical calculations were fully re-optimized by using the HF and DFT methods to estimate the total and relative energies of the different conformations. $D F T$ $\mathrm{B} 3 \mathrm{LYP} / 6-31 \mathrm{G}(\mathrm{d}, \mathrm{p})$ and $\mathrm{B} 3 \mathrm{LYP} / 6-31+\mathrm{G}(\mathrm{d}, \mathrm{p})$ optimizations using Gaussian $98^{15}$ were performed.

\section{Results and Discussion}

It is well known that the calix[5]arene and calix[4]arene form strong intramolecular hydrogen bonds among $\mathrm{OH}$ groups and represent the cone conformer as the most stable structure ${ }^{2-4}$ Substitution of all the phenolic protons of a $p$ tert-butylcalix[4]arene by a bulky alkyl group generally leads to conformationally rigid structures like the tetraethyl ester of $p$-tert-butylcalix[4]arene. ${ }^{6}$ However, when the substituent is small enough such as a methyl group, the resulting tetramethyl ether of $p$-tert-butylcalix[4]arene is no longer rigid, and any anisole ring can rotate via oxygen-throughthe-annulus to give a mixture of the four possible conformers. $^{7-1 i j}$

The $p$-tert-butylcalix[5]arene (1) and p-tert-butylcalix[4]arene (2) are identical with respect to the numbers of up/ down conformations that are possible, and for convenience the same descriptive names are used for both: cone, partial cone, 1,2-alternate or 1,3-alternate. The DFT optimizations without any constraint were carried out for four conformers of the 1 and 2 . 
Table 1. DFT B3LYP Optimized Relative Energies" of the Various Conformers of 1 ( $t$-Butylcalix[5]arene)

\begin{tabular}{lcccc}
\hline Calculation & \multicolumn{2}{c}{$D F T$ B3LYP } & HF & AM1 \\
\cline { 2 - 5 } Method & $6-31+\mathrm{G}(\mathrm{d}, \mathrm{p})$ & $6-31 \mathrm{G}(\mathrm{d}, \mathrm{p})$ & $6-31 \mathrm{G}$ & Semi-empirical \\
\hline Conformer & \multicolumn{1}{c}{$\Delta E$} & \multicolumn{1}{c}{$\Delta E$} & \multicolumn{1}{c}{$\Delta E$} & $\Delta E$ \\
\hline 1 (cone) & 0.00 & 0.00 & 0.00 & 0.00 \\
1 (partial cone) & 9.70 & 11.07 & 16.03 & 7.36 \\
1 (1.2-altemate) & 5.09 & 8.38 & 5.22 & 4.59 \\
1 (1.3-alternate) & 15.15 & 16.58 & 22.59 & 9.76 \\
\hline
\end{tabular}

" $\Delta E$ is the relatise energy $(\mathrm{kcal} / \mathrm{mol})$ with respect to the most stable cone conformation of the free host. Ertor limits in these calculations are about $0.01 \mathrm{kcalimol}$.

Table 2. DFT B3LYP Optimized Relative Energies" of the Various Conformers of 2 ( $t$-Butylcalix[4] arene)

\begin{tabular}{lcccc}
\hline Calculation & \multicolumn{2}{c}{$D F T$ B3LYP } & HF & AM1 \\
\cline { 2 - 5 } Method & $6-31+\mathrm{G}(\mathrm{d}, \mathrm{p})$ & $6-31 \mathrm{G}(\mathrm{d}, \mathrm{p})$ & $6-31 \mathrm{G}$ & Semi-empirical \\
\hline Conformer & \multicolumn{1}{c}{$\Delta E$} & \multicolumn{1}{c}{$\Delta E$} & \multicolumn{1}{c}{$\Delta E$} & \multicolumn{1}{c}{$\Delta E$} \\
\hline $\mathbf{2}$ (cone) & 0.00 & 0.00 & 0.00 & 0.00 \\
$\mathbf{2}$ (partial cone) & 8.45 & 10.35 & 12.13 & 6.64 \\
$\mathbf{2}$ (1.2-altennate) & 11.59 & 13.34 & 16.02 & 9.03 \\
$\mathbf{2}$ (1.3-alternate) & 14.21 & 17.31 & 22.35 & 11.11 \\
\hline
\end{tabular}

"See the footnote of the Table 1.

Table 1 shows the relative energies of the four distinct conformers of $p$-tert-butylcalix[5]arene (1) optimized by the $D F T$ calculations as well as other methods. All of the calculation results suggest that the cone conformer is the most stable among the conformational isomers of $\mathbf{1}$ in the following order: cone $>1,2$-alternate $>$ partial-cone $>1,3-$ alternate. For completeness and in order to keep in touch with other theoretical studies of related systems, we also report the results based on DFT, HF and AMl optimizations for the conformers of $p$-tert-butylcalix[4]arene (2). Table 2 shows the relative energies of the four contormers of 2 . All of the calculation results also suggest that the cone conformer is the most stable one among the conformational isomers of $\mathbf{2}$. However, the order of relative stability (cone > partial-cone $>1,2$-alternate $>1,3$-alternate) is different from $\mathbf{1}$.

The primary factors affecting the relative stabilities of the various conformers of the $t$-butylcalix[4 or 5] arene are the number and strength of the intramolecular hydrogen bonds. The good stability of 1,2-alternate conformer of $t$-butylcalix[5]arene (1) among less stable conformers can be explained by the four hydrogen bonds in $\mathbf{1}(1,2$-alternate), whereas $\mathbf{1}$ (partial-cone) has three $\mathrm{H}$-bonds and $\mathbf{2}$ (1,2-alternate) has only two H-bonds. We will explain the characteristics of the hydrogen bonds in various conformers later in this section.

The B $3 \mathrm{LYP} / 6-31+\mathrm{G}(\mathrm{d}, \mathrm{p})$ calculated relative stabilities of the conformations of $\mathbf{1}$ in Table 1 suggest that the cone conformer is $5.09 \mathrm{kcal} / \mathrm{mol}$ more stable than 1,2 -alternate, $9.70 \mathrm{kcal} / \mathrm{mol}$ more stable than partial-cone, and $15.15 \mathrm{kcal} /$ mol more stable than 1,3-alternate analogue, respectively. However, The B3LYP/6-31+G(d,p) calculated relative stabilities of the conformations of $\mathbf{2}$ in Table 2 suggest that the

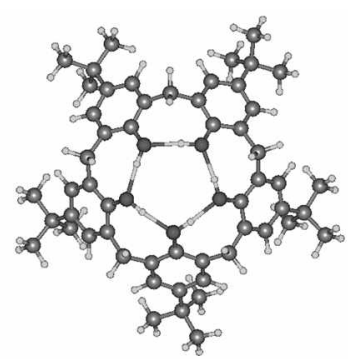

(a) cone (bottom view; PosMol)

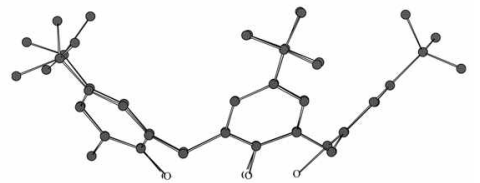

(b) cone (side view; Chem3D)

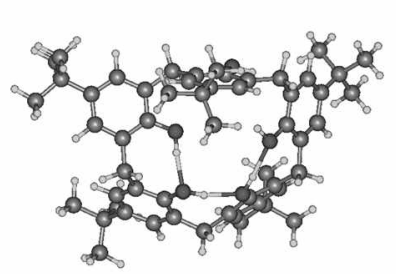

(c) partial-cone (bottom view; PosMol)

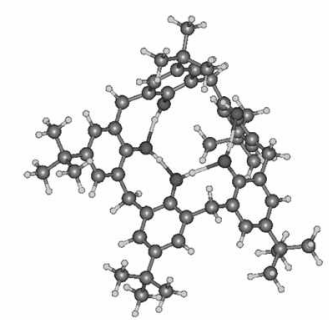

(e) 1,2-alternate (bottom view; PosMol)

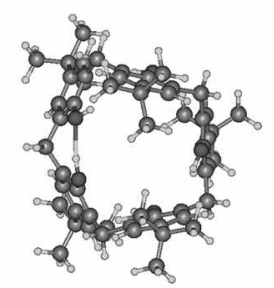

(g) 1,3-altemate (bottom view; PosMol)

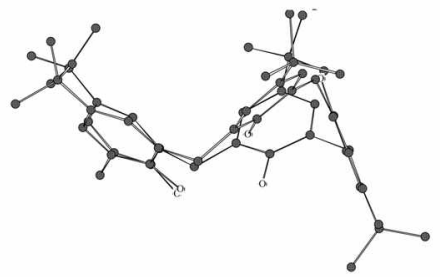

(d) partial-cone (side view; Chem3D)

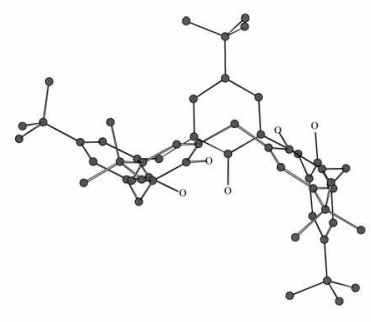

(f) 1,2-alternate (side view; Chem3D)

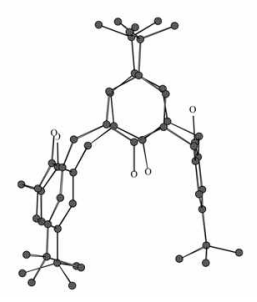

(h) 1,3-altemate (side view; Chem3 3D)
Figure 1. DFT B3LYP $/ 6-3]+\mathrm{G}(\mathrm{d}, \mathrm{p})$ optimized molecular structures of the conformers of 1 ( $p$-tert-butylcalix[5]arene). (a) Bottom view of the cone conformer by PosMol ${ }^{22}$ with hydrogen bonds shown, (b) side view of the cone conformer by Chem3 $3 \mathrm{D}^{23}$ without hydrogen atoms. (c) bottom view of the partial-cone confomer. (d) side view of the partial-cone confomer. (e) bottom view of the 1,2alternate conformer. (f) side view of the 1,2-alternate conformer, (g) bottom view of the 1,3-alternate conformer, and (h) side view of the 1.3-altemate confomer. Atons that are within a certain distance (the bond proximate distance) from one another were automatically marked as bonded.".

cone conformer is $8.45 \mathrm{kcal} / \mathrm{mol}$ more stable than partialcone, $11.59 \mathrm{kcal} / \mathrm{mol}$ more stable than 1,2-alternate, and $14.21 \mathrm{kcal} / \mathrm{mol}$ more stable than 1,3-alternate analogue, respectively. In the case of the original calix[4]arene without p-tert-butyl group, the relative stability was calculated in different order, where 1,3-alternate conformer had slightly better stability than the 1,2-alternate analogue ${ }^{7 / 1}$ For the calix[4]hydroquinone (CHQ), the order in stability is as follows: cone $>$ partial cone $>1,2$-alternative $>1,3$-alternative, where the cone conformer is $11.6 \mathrm{kcal} / \mathrm{mol}$ more 


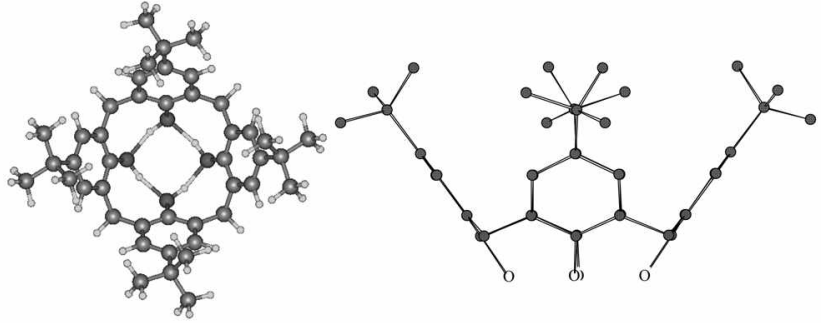

(a) Cone (top view; PosMol)

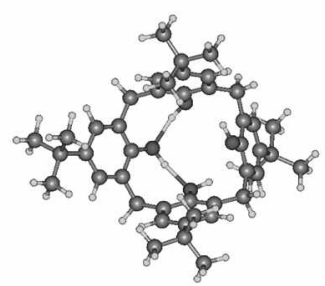

(c) 1-partial-cone(top view; PosMol)

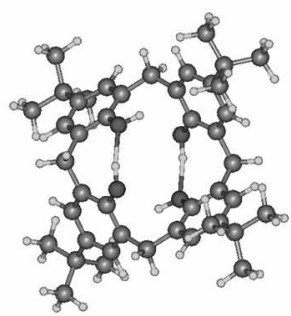

(e) 1,2-alternate (top view; PosMol)

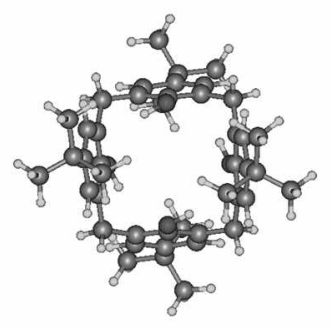

(g) 1,3-alternate (top view; PosMol) (b) Cone (side view; Chem3D)

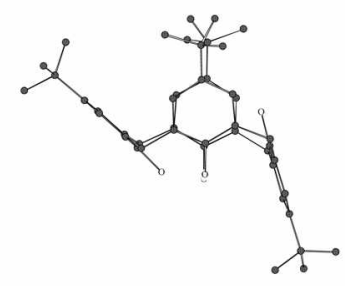

(d) 1-partial-cone(side view; Chem3D)

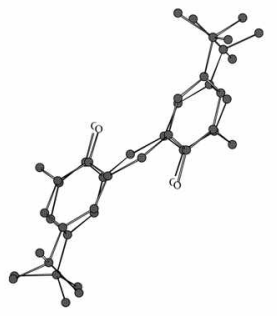

(f) 1,2-alternate (side view; Chem3D)

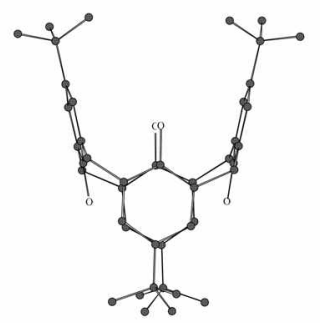

(h) 1,3-alternate (side view; Chem3D)

Figure 2. DFT B3LYP/6-31+G(d.p) optimized molecular struetures of the conformers of 2 (p-tert-butylcalix[4]arene). (a) Top view of the cone confomer by PosMol ${ }^{22}$ with hydrogen bonds shown, (b) side view of the cone conformer by Chem $3 \mathrm{D}^{35}$ without hydrogen atoms. (c) top view of the partial-cone conformer. (d) side view of the partial-cone conformer. (e) top view of the 1.2altemate conformer. (f) side view of the 1.2-altemate conformer. (g) top view of the 1.3-altemate conformer. and (h) side view of the 1,3-alternate conformer.

stable than partial-cone, $18.3 \mathrm{kcal} / \mathrm{mol}$ more stable than $1,2-$ alternate, and $19.8 \mathrm{kcal} / \mathrm{mol}$ more stable than 1,3 -alternate analogue, respectively. ${ }^{\text {la }}$

Figure 1 shows the DFT B3LYP/6-31+G(d.p) optimized stable structures showing hydrogen bondings of the various contormers of the p-tert-butylcalix[5]arene (1). 1 (cone) (Figure 1(a) having five hydrogen bonds is the most stable, and 1 (1,2-alternate) (Figure 1(e)) having four hydrogen bonds is next in the order. Experimental studies show that it also exists in a cone conformation. ${ }^{2 b, 18,19}$ The ordering of less stable conformers is a kind of unusual outcome, since the

adjacent $t$-butylbenzene rings of 1,2-alternate conformer may produce more steric hindrance than other cases such as partial-cone and 1,3-alternate. However, four hydrogen bondings of the 1,2-alternate conformer overcome the more interferences.

Figure 2 shows the DFT B3LYP/6-31+G(d,p) optimized stable structures showing hydrogen bondings of the various conformers of the tert-butylcalix[4]arene (2). The cone conformer ( 2 (cone): Figure 1(a)) having four hydrogen bonds is the most stable, and 2 (partial-cone: Figure 1(e) having two hydrogen bonds is next in the order.

In order to show the relationship between the stability and the hydrogen bonds, we have listed the number of $\mathrm{H}$-bonds and the B3LYP/6-31+G(d,p) calculated relative energies of the conformers of $\mathbf{1}$ and $\mathbf{2}$ in the Table 3. Each additional hydrogen bond contributes $4-5 \mathrm{kcal} / \mathrm{mol}$ better stability of the conformers of $\mathbf{1}$ and $\mathbf{2}$, if we ignore other effects such as steric hindrances.

Table 4 lists the DFT calculated distances and angles of intramolecular hydrogen bonds of 1 . In general, if $\mathrm{O} \cdots \mathrm{O}$ distance is less than $3.0 \AA$, one interprets that the $(\mathrm{O}-\mathrm{H} \cdots \mathrm{O})$ hydrogen bond is relatively strong for this intramolecular case. ${ }^{16}$ The $\mathrm{O} \cdots \mathrm{O}$ distances of $2.76-2.86 \AA$ in Table 4 sug-

Table 3. The Number of the H-bonds and DFT B3LYPi6$31+\mathrm{G}(\mathrm{d} . \mathrm{p})$ Relative Energies $s^{\prime t}$ of the Various Conformers of 1 and 2

\begin{tabular}{|c|c|c|c|c|c|}
\hline Conformer & $\begin{array}{c}\text { ti of } \\
\text { H-bond }\end{array}$ & $\Delta E$ & Confomer & $\begin{array}{c}\# \text { of } \\
\text { H-bond }\end{array}$ & $\Delta E$ \\
\hline 1 (cone) & 5 & 0.00 & 2 (cone) & 4 & 0.00 \\
\hline 1 (pautial cone) & 3 & 9.70 & 2 (partial cone) & 2 & 8.45 \\
\hline 1 (1,2-altemate) & 4 & 5.09 & 2 (1,2-alternate) & 2 & 11.59 \\
\hline 1 (1,3-altemate) & 1 & 15.15 & 2 (1,3-alternate) & 0 & 14.21 \\
\hline
\end{tabular}

Table 4. Calculated ${ }^{\prime \prime}$ Average Distances $(\AA)$ and Angles of Intramolecular $(\mathrm{O}-\mathrm{H} \cdots \mathrm{O})$ Hydrogen Bonds of 1 ( $t$-Butylcalix[5]arene)

\begin{tabular}{|c|c|c|c|c|c|}
\hline Contomer & H-bond & AMl & $\mathrm{HF}$ & B3LYP & B3LYP+ \\
\hline \multirow{4}{*}{$\overline{\mathbf{1}_{\text {ictore }}}$} & $0 \cdots 0$ & 3.071 & 2.753 & 2.762 & 2.765 \\
\hline & $\mathrm{H} \cdots \mathrm{O}$ & 2.120 & 1.800 & 1.780 & 1.783 \\
\hline & $\mathrm{O}-\mathrm{H}$ & 0.972 & 0.966 & 0.986 & 0.986 \\
\hline & Angle( & 166.1 & 168.1 & 174.5 & 173.1 \\
\hline \multirow[t]{4}{*}{ 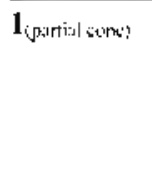 } & $\mathrm{O} \cdots \mathrm{O}$ & 3.111 & 2.791 & 2.808 & 2.810 \\
\hline & $\mathrm{H} \cdots \mathrm{O}$ & 2.159 & 1.847 & 1.837 & 1.841 \\
\hline & $\mathrm{O}-\mathrm{H}$ & 0.971 & 0.960 & 0.979 & 0.979 \\
\hline & Angle $\left({ }^{\circ}\right)$ & 168.7 & 166.9 & 171.6 & 170.1 \\
\hline \multirow[t]{4}{*}{ 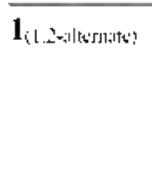 } & $0 \cdots 0$ & 3.066 & 2.748 & 2.765 & 2.768 \\
\hline & $\mathrm{H} \cdots \mathrm{O}$ & 2.160 & 1.835 & 1.816 & 1.823 \\
\hline & $\mathrm{O}-\mathrm{H}$ & 0.972 & 0.962 & 0.981 & 0.982 \\
\hline & Angle $\left({ }^{\circ}\right)$ & 158.1 & 158.8 & 163.0 & 162.3 \\
\hline \multirow[t]{4}{*}{$\mathbf{1}_{\text {(1...nallesmate) }}$} & $0 \cdots 0$ & 3.196 & 2.884 & 2.859 & 2.861 \\
\hline & $\mathrm{H} \cdots \mathrm{O}$ & 2.228 & 1.949 & 1.887 & 1.890 \\
\hline & $\mathrm{O}-\mathrm{H}$ & 0.972 & 0.958 & 0.976 & 0.976 \\
\hline & Angle (') & 173.0 & 165.2 & 173.0 & 172.6 \\
\hline
\end{tabular}

"AM1 semi-empirical, HFi6-31G DFT B3LYP:6-31G(d,p) and B3LYP/ $6-31 \mathrm{G}+(\mathrm{d}, \mathrm{p})$. 
Table 5. Experimental Distances $(\mathrm{O} \cdots \mathrm{O})$ of Intramolecular Hydrogen Bonds of Calixarenes

\begin{tabular}{|c|c|}
\hline Molecule (CSD entry) ${ }^{17}$ & Average ( $\AA$ ) \\
\hline Calix[5]arene (UKAGIW) ${ }^{18}$ & 2.764 \\
\hline Calix [5] arene (VETYAV) ${ }^{14}$ & 2.780 \\
\hline 1 (VETXUO) $^{16}$ & 2.894 \\
\hline $2(\mathrm{XAHMOI})^{20}$ & 2.779 \\
\hline Calix [4]crown-5-ether (VERLUA) ${ }^{2 l}$ & 2.727 \\
\hline
\end{tabular}

Table 6. Calculated" Average Distances $(\AA)$ and Angles of Intramolecular $(\mathrm{O}-\mathrm{H} \cdots \mathrm{O}) \mathrm{Hydrogen}$ Bonds of 2 ( $t$-Butylealix[4]arene)

\begin{tabular}{|c|c|c|c|c|c|}
\hline Conformer & H-bond & AM1 & $\mathrm{HF}$ & B3LYP & B3LYP+ \\
\hline \multirow{4}{*}{$\overline{2 \text { iconci }}$} & $0 \cdots 0$ & 2.918 & 2.654 & 2.647 & 2.650 \\
\hline & $\mathrm{H} \cdots \mathrm{O}$ & 2.055 & 1.740 & 1.677 & 1.683 \\
\hline & $\mathrm{O}-\mathrm{H}$ & 0.970 & 0.965 & 0.991 & 0.991 \\
\hline & Angle $\left(^{\circ}\right)$ & 147.3 & 156.6 & 164.7 & 164.0 \\
\hline \multirow[t]{4}{*}{$\mathbf{2}_{\text {ijartial-ionei }}$} & $0 \cdots 0$ & 3.015 & 2.728 & 2.711 & 2.718 \\
\hline & $\mathrm{H} \cdots \mathrm{O}$ & 2.121 & 1.819 & 1.758 & 1.767 \\
\hline & $\mathrm{O}-\mathrm{H}$ & 0.971 & 0.961 & 0.982 & 0.982 \\
\hline & Angle( $\left.{ }^{\circ}\right)$ & 155.9 & 158.4 & 164.0 & 163.5 \\
\hline \multirow[t]{4}{*}{ 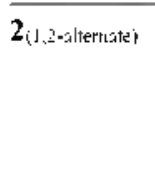 } & $0 \cdots 0$ & 3.082 & 2.766 & 2.783 & 2.796 \\
\hline & $\mathrm{H} \cdots \mathrm{O}$ & 2.137 & 1.849 & 1.825 & 1.842 \\
\hline & $\mathrm{O}-\mathrm{H}$ & 0.972 & 0.960 & 0.979 & 0.978 \\
\hline & Angle( $\left.{ }^{(}\right)$ & 163.6 & 158.9 & 165.6 & 164.2 \\
\hline
\end{tabular}

2(1,3-alternatei none

"See the footnote of the Table 4

gest that our calculated values in the p-tert-butylcalix[5]arene (1) are in accord with the experimental distances (2.76-2.89 $\AA$ in Table 5) of the intramolecular hydrogen bonds $(\mathrm{O} \cdots \mathrm{O})$ of the calixarenes obtained from Cambridge Structure Database. ${ }^{17}$ Also, one recognizes that the $(\mathrm{O}-\mathrm{H} \cdots$ $\mathrm{O})$ hydrogen bond is stronger if the $(\mathrm{O}-\mathrm{H} \cdots \mathrm{O})$ angle is closer to $180^{\circ}$. Our calculated $(\mathrm{O}-\mathrm{H} \cdots \mathrm{O})$ angles of $154^{\circ}$ $175^{\circ}$ in Table 4 tell that the hydrogen bondings in the molecule (1) are pretty strong.

In order to compare our calculated $\mathrm{H}$-bond distances of 1 with the values of the strong intramolecular hydrogen bonds of $t$-butylcalix[4]arene (2), we have tabulated the $D F T$ calculated $\mathrm{H}$-bond distances of $\mathbf{2}$ (Table 6). The average calculated distances (2.65-2.80 $\AA$ in Table 6 ) of the intramolecular hydrogen bonds of $t$-butylcalix[4]arene (2) are shorter than the values $(2.76-2.86 \AA$ in Table 4$)$ of p-tertbutylcalix[5]arene (1). FTIR studies already confirmed the intramolecular character of the bonding and showed that it is strongest for the cyclic tetramer (2) and weakest for the cyclic pentamer $(\mathbf{1}) .^{24}$

We have also tabulated the hydrogen-bond distances of lower level calculation methods (see Table 4 for $\mathbf{1}$ and Table 6 for 2), and found an interesting outcome. The semiempirical AM1 optimized average $\mathrm{H}$-bond distances (2.92$3.20 \AA$ ) in $\mathbf{1}$ and $\mathbf{2}$ are always -0.30 longer than the values of ab initio $\mathrm{HF}(2.75-2.88 \AA)$ and $D F T(2.76-2.86 \AA)$ methods which are much closer to the experimental results (2.76-2.89 $\AA$ in Table 5). These calculation results suggest us that the
AM1 optimized H-bond distances are too long and that one should be careful for the discussion of the hydrogen bonding using the semi-empirical calculation method. ${ }^{25}$

\section{Conclusion}

The relative stabilities of the conformers of the $t$-butylcalix[5]arene (1) and t-butylcalix[4]arene (2) are mainly dependent upon the number and strength of the intramolecular hydrogen bonds than steric hindrance of adjacent rings. The relative stability of the various conformers of $\mathbf{1}$ is in the following order: cone (most stable) $>1,2$-alternate $>$ partialcone $>1,3$-alternate. The relative stability of the different conformers of $\mathbf{2}$ is in the following order: cone (most stable) $>$ partial-cone $>1,2$-alternate $>1,3$-alternate.

Each hydrogen bond contributes $4-5 \mathrm{kcal} / \mathrm{mol}$ for the stability of the conformers of 1 and 2 . The ${ }^{-{ }^{*}} \mathrm{O}$ distances of 2.76-2.86 $\AA$ suggest that the DFT optimized values in the molecule 1 are in accord with the experimental distances $(2.76-2.89 \AA)$ of the intramolecular hydrogen bonds $(\mathrm{O} \cdots \mathrm{O})$ of the calix[5]arenes.

Acknowledgments. This research was supported by the Chung-Ang University research scholarship grants in 2008. The large portions of the computations were carried out with use of the computer facilities at the Research Center for Computational Science of the Okazaki National Research Institutes in Japan.

\section{References}

1. (a) Caliratenes in Action; Mandolini, L.; Ungaro, R., Eds.; World Scientific Publishers Co.: Singapore, 2007. (b) Gutsche, C. D. Calixwenes Revisited; Royal Society of Chemistry: Cambridge, 1998. (c) Calixarenes $50^{\text {th }}$ Anniversary: Commemorative Folume; Vicens, J.; Astari, Z.; Harrowfield, J. . M., Eds.; Kluwer Academic Publishers: Dordrecht, The Netherlands, 1991. (d) Gutsche, C. D. Colixurenes; Royal Society of Chemistry: Cambridge, 1989. (e) Calixarenes: A Versatile Class of Macrocticlic Compounds; Vicens, J.; Bohmer, V., Eds.; Kluwer Academic Publishers: Dordrecht, The Netherlands, 1991. (t) Jeon, Y.-M.; Lim, T.-H.; Kim, J.-G.; Kim, J.-S.; Gong, M.-S. Bull. Korean Chem. Soc. 2007, 28, 816. (g) Tan, L. V.; Quang, D. T.; Lee, M. H.; Kim, T. H.; Kim, H.; Kim, I. S. Bull. Korewn Chem. Soc. 2007, 28,791.

2. (a) Coruzzi, M.; Andreetti, G D.; Bocchi, A.; Ungaro, R. J. Chem. Soc., Perkin Trans. 1982, 2, 1133. (b) Barrett, G.; AcKervey, M. A: Malone, J. F.; Walker, A.; Anaul-Neu, F.; Guerra, L; Schwing-Weill, M.-J. J. Chem. Soc. Perkin Trans. $21993,1475$. (c) Stewart, D. R.; Krawiec, M.; Kashyap, R. P.; Watson, W. H.; Gutsche, C. D. I. An. Chem. Soc. 1995, 117, 586. (d) Gordon, I. L. M.; Bohmer, V.; Vogt, W. Tetrahedron Lett. 1995, 36, 2445. (e) Pappalardo, S.; Parisi, M. F. J. Org. Chen. 1996, 61, 8724. (f) Amaud-Neu, F.; Fuangswasdi, S.; Notti A.; Pappalardo, S.; Parisi, M. Angen: Chem. Int. Ed. 1998, 37, 112. (g) Giannetto, M.; Mori, G.; Norti, A.; Pappalardo, S.; Paris, M. F. Anal. Chem. 1998, 70 , 4631. (h) Salvo, G D.; Gattuso, G; Notti, A.; Parisi, M.; Pappalardo, S. J. Org. Chem. 2002, 67, 684 .

3. (a) Ninagawa, A ; Matsuda, H. Makromol Chen Rapid Conmm. 1982, 3, 65. (b) Markowitz, M. A.; Janout, V.; Castner, D. G; Regen, S. L. J. Am. Chem. Soc, 1989, 11,8192 . (c) Souley, B; Astari, Z.; Vicens, J. Polish J. Chem. 1992, 66, 959. (d) Kamerer, H.; Happel, G.; Mathiasch, B. Mokromol. Chem. 1981, $182,1685$. 
(e) Souley, B.; Asfari, Z; Vicens, T. Polish J. Chem. 1993, 67, 763. 4. (a) Gutsche, C. D. Top. Curv: Chem. 1984, 123, 1. (b) Gutsche, C. D. Acc. Chem Res. 1983, 16, 161. (c) Andreetti, G D.; Lngaro, R.; Pochini, A. J. Chem. Soc, Chem. Comm. 1979, 1005. (d) Grootenhuis, P. D. J.; Kollman, P. A.; Groenen, L. C.; Reinhoudt, D. N.; van Hummel, G. J.; Ugozzoli, F.; Andreetti, G. D. $J$. Am. Chem. Soc. 1990, 112,4165 .

5. (a) Gutsche, C. D.; Iqbal, M. Org 5in. 1990, 68, 234. (b) Groonen, L. C.; van Loon, J.-D.; Verboom, W.; Harkema, S.; Casnati, A.; Ungaro, R.; Pochini, A.; Lgozzoli, F.; Reinhoudt, D. N. J. Am. Chem. Soc. 1991, $113,2385$.

6. Choe, J.-I; Lee, S. H.; Oh, D.-S.; Chang, S.-K.; Naubu, S. Bulll. Korem Chem. Soc. 2004, 25, 190.

7. (a) Harada, T; Rudzinski, J. M.; Shinkai, S. J. Chem. Soc. Perkin Trons. 1992, 2, 2109. (b) Harada, T.; Rudzinski, I. M.; Shinkai, S. Tetrohedron 1993, 49, 5941. (c) Harada, T; Ohseto, F.; Shinkai, S. Tetrahedron 1994, 50, 13377. (d) van Hoom, W. P.; Morshuis, . . G. H.; van Veggel, F. C. J. M.; Reinhoudt, D. N. J. Phss. Chem. 1998, 102, 1130. (e) van Hoorn, W. P.; Briels, W. T; van Duynthoven, I. P. M.; van Veggel, F. C. J. M.; Reinhoudt, D. N. $J$. Org. Chem. 1998, 63, 1299. (f) Blixt, T.; Detellier, C. J. Ant Chent. Soc. 1995, 117 , 8536. (g) Fukazawa, Y; Yoshimura, K.; Sasaki, S.; Yamazaki, .M.; Okajima, T. Tetrahedron 1996, $52,2301$.

8. (a) Bemardino, R. J.; Costa Cabral, B. J. J. Phis. Chem. A 1999 , 103, 9080 . (b) Bernardino, R. J.; Costa Cabral, B. J.; Pereira, J. L. C. J. Mol SFHC. (THEOCHEM 1998, 23, 455 .

9. (a) Kim, K. S.; Suh, S. B.; Kim, J. C.; Hong, B. H.; Lee, E. C.; Yun, S.; Tarakeshwar, P.; Lee, J. Y.; Kim, Y.; Ilum, H.; Kim, H. G; Lee, J. W; Kim, J. K.; Lee, H. M.; Kim, D.; Cui, C.; Youn, S. J.; Chung, H. Y.; Choi, H. S.; Lee, C.-W.; Cho, S. J.; Jeong, S.; Cho, J.-H. J. Am. Chent Soc. 2002, 124, 14268. (b) Riehn, C.; Reimann, B.; Buchhold, K.; Barth, H.-D.; Vaupel, S.; Brutschy, B.; Tarakeshwar, P.; Kim, K. S. J. Chem. Phts. 2001, $115,10045$.

10. Choe, J.-1.; Lee, S. H.; Oh, D.-S. Bull. Korean Chem. Soc. 2004, 25,55 .

11. Choe, J.-1.; Chang, S.-K. Bull. Korean Chem. Soc. 2002, 23, 48.

12. (a) Choe, T,-I; Chang, S.-K.; Satoshi, M.; Nanbu, S. Bull. Korean Chem. Soc. 2003, 24, 75. (b) Choe, T.-I.; Lee, S. H. Bull. Korean Chem. Soc. 2004, $25,553$.
13. HyperChen Release 7.5; Hypercube, Inc: Waterloo, Ontario, Canada, 2002.

14. Choe, J.-I.; Kim, K.; Chang, S.-K. Bml. Korewn Chem. Soc. 2000, 21,465 .

15. Frisch, M. J.; Trucks, G. W.; Schlegel, H. B.; Scuseria, G E.; Robb, M. A.; Cheeseman, J. R.; Zakrzewski, V. G.; Montgomery, J. A., Jr.; Stratmann, R. E.; Burant, J. C.; Dapprich, S.; Millam, J. M.; Daniels, A. D.; Kudin, K. N.; Strain, M. C.; Farkas, O.; Tomasi, I.; Barone, V.; Cossi, M.; Cammi, R.; Mennucci, B.; Pomelli, C.; Adamo, C.; Clifford, S.; Ochterski, J.; Petersson, G. A.; Ayala, P. Y.; Cui, Q.; Morokuma, K.; Malick, D. K.; Rábuck, A. D.; Raghavachari, K.; Foresman, J. B.; Cioslowski, J.; Ortiz, J. V.; Baboul, A. G; Stefanov, B. B.; Liu, G.; Liashenko, A.; Piskorz, P.; Komaromi, I.; Gomperts, R.; Martin, R. L.; Fox, D. I.; Keith, T.; Al-Laham, M. A.; Peng, C. Y.; Nanayakkara, A.; Challacombe, M.; Gill, P. M. W.; Johnson, B.; Chen, W.; Wong, M. W.; Andres, J. L.; Gonzdez, C.; Head-Gordon, M.; Replogle, E. S.; Pople, J. A. Gaussian 98. Revision A.11.3; Gaussian, Inc.: Pittsburgh, PA, 1998 .

16. (a) Jeffrey, G. A. An Introdiction to Hudogen Bonding; Oxford Lniv. Press: Cambridge, 1997 (b) Pak, C.: Lee, H. M.; Kim, J. C.; Kim, D.; Kim, K. S. Strict. Chem. 2005, 16, 187.

17. Cambridge Structure Database; Cambridge Crystallographic Data Centre: Cambridge, U. K., 2008.

18. Atwood, I. L.; Barbour, L. J.; Heaven, M. W.; Raston, C. L. Angen: Chem. 2003, 42,3254.

19. Clark, T. E.; Makha, M.; Raston, C. L.; Sobolev, A. N. Citst. Growth Des. 2006, 6, 2783 .

20. Brouwer, E. B.; Ldachin, K. A.; Enright, G D.; Ripmeester, J. A. Chem.Commm. 2000, 1905.

21. Agnihotri, P.; Suresh, E.; Paul, P.; Ghosh, P. K. Eur: J. Inorg. Chen. 2006, 3369 .

22. Lee, S. J.; Chung, H. Y.; Kim, K. S. Bull. Korean Chem. Soc 2004, 25,1061 .

23. Chem 3D, Version 7.0; Cambridge Sott: Cambridge, MA, U.S.A., 2001.

24. Keller, S. W; Schuster, G M.; Tobiason, F. L. Polln. Mater: Sci. Eng. 1987, 57, 906.

25. Clark, T. J. Mol. Struc. Theocheni 2000, 530,1. 